\title{
The Transparency of Politics and the Quality of Politicians
}

\author{
By Andrea Mattozzi and Antonio Merlo*
}

Politics has always attracted the attention of the media, citizens organizations, and the general public. Recent years have also witnessed a global process of "spectacularization" of politics, which, among other things, has resulted in a dramatic increase in the amount of information available about many facets of political life.

Politicians, for example, are public figures, and much of what they do is now the object of close public scrutiny. Nevertheless, the extent to which various aspects of what goes on within the political sector are observable from the outside, which we refer to as the transparency of politics, still varies a great deal across countries. For example, while in some countries all individual votes in the legislature are part of the public record (e.g., the United States and Sweden), this is not the case in others (e.g., Italy and Spain). Also, while many democracies have adopted disclosure laws that require political parties and politicians to report all the contributions they receive (e.g., Canada and the United Kingdom), such laws are not in place in several other countries (e.g., Austria and Finland).

It is therefore interesting to ask whether the transparency of politics may be systematically related to political outcomes, and whether more transparency would lead to better outcomes. In particular, in this article, we analyze the relationship between the transparency of politics and the quality of politicians, and focus on the recruitment of politicians by political parties.

Parties represent a fundamental institution of representative democracy, and are the politicalsector analogues of firms in the market sector. By and large, politicians are affiliated with a party, and typically start their political careers

\footnotetext{
* Mattozzi: Division of Humanities and Social Sciences, California Institute of Technology, MC 228-77, Pasadena, CA 91125 (e-mail: andrea@hss.caltech.edu); Merlo: Department of Economics, University of Pennsylvania, 3718 Locust Walk, Philadelphia, PA 19104 (e-mail: merloa@econ.upenn. edu). Financial support from National Science Foundation grant SES-0617901 is gratefully acknowledged.
}

by working for party organizations (see, e.g., Heinrich Best and Maurizio Cotta 2000). Hence, the recruiting decisions of parties determine the quality of the pool of politicians.

As in Andrea Mattozzi and Antonio Merlo (2006), we model the situation faced by a political party that has to recruit new politicians. Potential recruits are heterogeneous with respect to their political skills, and may either work for the party and become professional politicians or find alternative employment in the market sector. Political skills are valuable in the political sector and are observable by the party. In fact, people who are interested in becoming politicians typically begin their involvement in politics by engaging in a variety of unpaid political activities that are organized and monitored by political parties (e.g., student political organizations, campaign teams, party internships). These activities provide opportunities for a political party to observe the quality of individuals it may be potentially interested in recruiting.

Political skills are also valuable in the market sector. They may be directly productive in certain occupations, for example, working for lobbying firms (see, e.g., Mattozzi and Merlo 2006), or indirectly valuable because they are positively correlated with other skills that are directly productive in other occupations (see, e.g., Mattozzi and Merlo 2005). As long as politics is not perfectly transparent, however, the political skills of individuals are only imperfectly observable by potential employers outside of the political sector, although the party's recruiting decisions also convey some information about the quality of its recruits.

The benefit to the political party of recruiting a new politician, which, for example, may be measured by the funds raised by the politician on behalf of the party, increases with the political skills of the recruit. The objective of the party, when making its recruiting decisions, is to generate rents, given by the difference between the funds raised by its recruits and the wages it has 
to pay them. Hence, each politician has to raise at least enough funds to cover his salary, which is determined in equilibrium by his outside option of working in the perfectly competitive market sector, where individuals are paid based on their expected political skills. In particular, the potential market wage of a party's recruit is equal to a weighted average of the individual's political skills and the average skills of politicians within the party, where the weight measures the transparency of politics.

We characterize the party's equilibrium recruiting rule, which determines the endogenous quality of the party's membership, and evaluate the effect of transparency on the quality of politicians. We find that an increase in the transparency of politics reduces the average quality of the politicians a party recruits in equilibrium.

To understand this result, it is useful to analyze the effect of a reduction in transparency, starting from the situation where politics is perfectly transparent, so that political skills are directly observable both within and outside the political sector. In this case, the wages of all potential recruits (regardless of whether they become politicians or work in the market sector) are determined solely by their individual political skills, and suppose that the market wages of the most skilled individuals exceed the amount of funds they could raise for the party, so that the party would not recruit them as politicians.

Now consider the situation where politics is not perfectly transparent, so that political skills are only imperfectly observable from outside the political sector. In this case, the party's equilibrium recruiting strategy conveys some information to the market sector about the skills of the party's recruits. This information externality affects the equilibrium wage the party has to pay to each of its recruits, which is equal to a weighted average between the recruit's political skills and the average skills of all of the party's recruits. This implies that as long as the party recruits individuals from a range of political skills, it can now afford to recruit relatively better politicians, since their market wages are lower than in the case where politics is perfectly transparent. At the same time, the market wages of individuals with relatively low political skills are now higher, thus not making it worthwhile for the party to recruit individuals at the bottom of the distribution of political skills, who may now be too expensive compared to the relatively low benefits they generate for the party. Overall, this results in an increase in the average quality of politicians, which is bigger the greater the information advantage the party has over the market sector (i.e., the less transparent politics is). ${ }^{1}$

\section{Model and Results}

We consider a situation where a political party, which is defined as a collection of politicians, has to recruit new members. Recruitment opportunities arrive randomly, and when an opportunity materializes the party has to decide whether to pursue it. The party can recruit as many politicians as it wants (i.e., adding a new member does not preclude the possibility of recruiting additional members). Hence, each recruiting decision can be analyzed independently.

There exists a set of individuals of measure one who are potentially interested in becoming politicians. Their alternative is to work in the (perfectly competitive) market sector. Individuals are heterogeneous with respect to their political skills $p$, which are uniformly distributed on $[0,1]$, and are valuable in the political sector as well as in the market sector. Each individual knows his own skills, which are also perfectly observable by the party, but not by the market sector.

\footnotetext{
${ }^{1}$ This article borrows heavily from our work on the careers of politicians and political recruitment contained in Mattozzi and Merlo (2005, 2006), where we develop the basic framework and some of the concepts that are used here. Our previous work, however, does not address the relationship between the transparency of politics and the quality of politicians, which is the focus of this article. Our work also relates to the literature on the role of parties in the selection of electoral candidates and, more generally, on the endogenous selection of politicians (see, e.g., the survey by Merlo 2006 and the references therein). The focus of this literature, however, is quite different form the objective of our article. There is a recent related literature that studies the effects of transparency in a variety of political institutions, for example, elections, committees, legislatures, and bureaucracies (see, e.g., Andrea Prat 2005; Ernesto Dal Bo 2006; Alessandro Gavazza and Alessandro Lizzeri 2006; Gilat Levy 2007, and the other articles included in this session). Like the results in our article, this literature finds that increasing transparency does not necessarily lead to better outcomes.
} 
If an individual with political skills $p \in[0,1]$ joins the party, he raises an amount of funds for the party equal to $y(p)=\gamma p^{\alpha}$, where $\alpha \in(0,1)$, and $\gamma \in(0,1 / 2]$. Hence, the fund-raising technology $y(p)$ is described by a standard production function, which is increasing and concave. If the party recruits the individual, the party's payoff is equal to $y(p)-w^{P}(p)$, where $w^{P}(p)$ is the (endogenous) wage the party pays to the individual. If, on the other hand, the party does not recruit him, the party's payoff generated by the lost recruiting opportunity is equal to zero.

The political skills of individuals are only imperfectly observable outside of the political sector. Since they are known by the party, however, potential employers in the market sector can use the party's recruiting strategy to form beliefs about the expected skills of the party's recruits. To capture the aspects of the environment we are considering, we specify that the potential market wage of a party's recruit is equal to his expected political skills (based on the information available to the market sector), and is given by a weighted average of the recruit's own political skills and the average skills of a generic party's recruit. The parameter $\mu \in[0,1]$, which is the weight associated with an individual's own skills, denotes the transparency of politics, where $\mu=0$ corresponds to a situation where the market sector can observe only whether an individual is being recruited by the party, but has no additional information about potential recruits, and $\mu=1$ corresponds to the opposite extreme of complete transparency, where political skills are directly observable by the market sector. While this specification is clearly a reduced form, it can be derived from a more elaborate model of the market sector.

We are interested in characterizing the equilibrium recruiting strategy of the party, and, hence, the political skills of individuals who enter the political sector. More specifically, let $P \subseteq[0,1]$ be a finite union of nondegenerate intervals. A party structure $P$ is an equilibrium if and only if the following two conditions are satisfied for all $p \in P$ : (a) $y(p)-w^{P}(p) \geq 0$; and (b) $w^{P}(p) \geq \mu p+(1-\mu) E_{M}[P]$, where $E_{M}[P]$ denotes the expected skills of a generic party member from the point of view of the market sector, conditional on the party structure being $P$. Condition (a) requires that each member of the party raise at least enough funds for the party to pay for his own wage, and condition (b) implies that no prospective politician prefers to work in the market sector.

Suppose the party has the opportunity to recruit a generic individual with political skills $p$. Will the party pursue this opportunity? To answer this question, recall that the expected wage in the market sector of an individual with skills $p$ who is recruited by the party is equal to $\mu p+(1-\mu) E_{M}[P]$. It follows that the party will recruit the individual if and only if $y(p)-w^{P}(p) \geq 0$, where $w^{P}(p)=\mu p+(1-\mu)$ $E_{M}[P]$. Concavity of $y(p)$ implies that it is never profitable for the party to recruit individuals with skills belonging to disjoint intervals. Therefore, the party will be willing to recruit any individual with political skills belonging to an interval, as long as the party's rents generated by recruiting the individual are nonnegative. Hence, $P=$ $\left[p_{L}, p_{H}\right] \subseteq[0,1]$, where $p_{L}<p_{H}$.

Moreover, if $\gamma<(1+\mu) / 2$, the political party will never recruit the best possible politicians (i.e., individuals with political skills $p=1$ ). In fact, when $p_{H}=1$, it follows that

$$
\begin{aligned}
y(1)= & \gamma<\frac{1+\mu}{2}<\mu \cdot 1 \\
& +(1-\mu) \frac{1+p_{L}}{2}=w^{P}(1) .
\end{aligned}
$$

Hence, for $\gamma \in(0,1 / 2]$, we have that $p_{H}<1$.

We conclude that an equilibrium party structure $P=\left[p_{L}, p_{H}\right] \subset[0,1]$, where $p_{L}<p_{H}<1$, is a solution to the following system of equations:

$$
\begin{aligned}
& \gamma p_{L}^{\alpha}=\mu p_{L}+(1-\mu)\left[\left(p_{H}+p_{L}\right) / 2\right] \\
& \gamma p_{H}^{\alpha}=\mu p_{H}+(1-\mu)\left[\left(p_{H}+p_{L}\right) / 2\right] .
\end{aligned}
$$

The following proposition provides a necessary and sufficient condition for the existence and uniqueness of a solution to the system (1) above, which characterizes the equilibrium.

PROPOSITION 1: An equilibrium party structure $P=\left[p_{L}, p_{H}\right] \subset[0,1], p_{L}<p_{H}<1$, exists and is unique if and only if $\alpha<\mu$. 
PROOF:

By solving the first equation of system (1) in $p_{H}$, we get

$$
p_{H}\left(p_{L}\right)=\frac{2 \gamma p_{L}^{\alpha}-(1+\mu) p_{L}}{(1-\mu)},
$$

where $p_{H}\left(p_{L}\right)$ is a strictly concave function such that $p_{H}(0)=0$ and $p_{H}\left(p_{L}\right)>p_{L}$ if and only if $p_{L}$ $<\widetilde{p} \equiv \gamma^{1 /(1-\alpha)}<1$. By substituting $p_{H}\left(p_{L}\right)$ into the second equation of system (1), we get

$S\left(p_{L}\right) \equiv$

$$
\begin{aligned}
& \frac{\gamma\left(p_{H}\left(p_{L}\right)\right)^{\alpha}(1-\mu)-\gamma p_{L}^{\alpha}(1+\mu)+2 \mu p_{L}}{1-\mu} \\
& =0
\end{aligned}
$$

Note that system (1) always has two coincident solutions, namely $p_{L}=p_{H}\left(p_{L}\right)=0$ and $p_{L}=$ $p_{H}\left(p_{L}\right)=\tilde{p}$. Moreover,

$$
\lim _{p_{L} \rightarrow 0} S^{\prime}\left(p_{L}\right)>0,
$$

and

$$
\lim _{p_{L} \rightarrow \tilde{p}} S^{\prime}\left(p_{L}\right)=\frac{2(1-\alpha)}{1-\mu}(\mu-\alpha) \geq 0,
$$

if and only if $\mu \geq \alpha$. Therefore, when $\mu>\alpha$, system (1) always admits a solution. In order to show that $\mu>\alpha$ is also a necessary condition for existence, first notice that when $\alpha=\mu$, system (1) admits only coincident solutions. Suppose now that $\mu<\alpha$. By dividing the first equation of system (1) by the second equation, we get

$$
\left(\frac{p_{L}}{p_{H}}\right)^{\alpha}=\frac{\mu p_{L}+(1-\mu)\left[\left(p_{H}+p_{L}\right) / 2\right]}{\mu p_{H}+(1-\mu)\left[\left(p_{H}+p_{L}\right) / 2\right]},
$$

which can be rewritten as

$$
x^{-\alpha}=\frac{1+\mu+(1-\mu) x}{1-\mu+(1+\mu) x},
$$

where $x \equiv p_{H} / p_{L}>1$. Define

$$
G(x) \equiv x^{-\alpha}-\frac{1+\mu+(1-\mu) x}{1-\mu+(1+\mu) x},
$$

so that a solution to system (1) corresponds to a zero of $G(x)$. Note that

$$
\begin{gathered}
\lim _{x \rightarrow 1} G(x)=0, \\
G^{\prime}(x)=-\alpha x^{-\alpha-1}+\frac{4 \mu}{(1-\mu+(1+\mu) x)^{2}},
\end{gathered}
$$

and

$$
\lim _{x \rightarrow 1} G^{\prime}(x)=-\alpha+\mu<0 .
$$

Therefore, it cannot be that $G^{\prime}(x)<0$ in all equilibria. If, however, we evaluate $G^{\prime}(x)$ in equilibrium, we have that $\mu<\alpha$ implies that $G^{\prime}(x)<0$.

In order to show that the solution of system (1) is unique, first note that if there are multiple solutions, the limits of $S\left(p_{L}\right)$ computed above imply that the number of solutions must be generically odd. In particular, if there are three solutions 0 $<p_{L}^{\prime}<p_{L}^{\prime \prime}<p_{L}^{\prime \prime \prime}<\tilde{p}$, then it must be the case that $S^{\prime}\left(p_{L}^{\prime}\right)<0, S^{\prime}\left(p_{L}^{\prime \prime}\right)>0$, and $S^{\prime}\left(p_{L}^{\prime \prime \prime}\right)<0$. By evaluating $S^{\prime}\left(p_{L}\right)$ in equilibrium and rearranging terms, we have that $S^{\prime}\left(p_{L}\right)<0$ if and only if

$$
\begin{aligned}
& \frac{\left\{\begin{array}{l}
\gamma p_{L}^{\alpha-1}(1-\alpha)(1+\mu) \\
\times\left[1-\frac{2 \gamma p_{L}^{\alpha-1}(1+\alpha)-(1+\mu)}{1+\mu}\left(\frac{p_{L}}{p_{H}\left(p_{L}\right)}\right)^{1-\alpha}\right]
\end{array}\right\}}{(1-\mu)} \\
& \quad<0 .
\end{aligned}
$$

Since the sign of the expression above depends only on the term in square brackets, if this term is monotone in $p_{L}$ the solution must be unique. By taking the derivative with respect to $p_{L}$ of the term in square brackets and rearranging, we get

$$
\begin{aligned}
& \left(\frac{p_{H}\left(p_{L}\right)}{p_{L}}\right)^{\alpha} \frac{4 \gamma \alpha(1-\alpha)}{\left(1-\mu^{2}\right) p_{L}^{2}} \\
& \quad \times\left(\gamma \alpha p_{L}^{\alpha-1} \frac{1+\alpha}{\alpha}-(1+\mu)\right),
\end{aligned}
$$

where the sign of this expression is equal to the sign of the last term. When $\mu>\alpha$, we have that

$$
\gamma \alpha p_{L}^{\alpha-1} \frac{1+\alpha}{\alpha}-(1+\mu)>\frac{\mu}{\alpha}-1>0
$$


since, in equilibrium, concavity of $y(p)$ implies that $\gamma \alpha p_{L}^{\alpha-1}>\mu>\gamma \alpha p_{H}^{\alpha-1}$.

Note that in equilibrium the party recruits only mediocre politicians. It does not pursue either the very best or the worst political talent potentially available. This result also arises in the model we study in Mattozzi and Merlo (2006). In that model, however, the result is due to an equilibrium effect that forces the party to forego the opportunity of recruiting the very best politicians, in spite of the fact that in principle the party could afford to recruit individuals of all skill levels, including the very best. On the other hand, in the environment we consider here, the result is a direct consequence of the assumption that the party can never afford to recruit individuals with the highest level of political skills (which is the case if $\gamma \leq 1 / 2$ ). In equilibrium, the party is not willing to recruit individuals with either very low or very high political skills since they do not generate enough rents relative to the wages the party has to pay them.

The next proposition establishes the comparative statics property of the unique equilibrium.

PROPOSITION 2: An increase in the transparency of politics (i.e., an increase in $\mu$ ) reduces the average quality of politicians.

\section{PROOF:}

The result follows from applying the Implicit Function Theorem to $S\left(p_{L}\right)=0$. In the unique equilibrium,

$$
\begin{aligned}
& \frac{\partial p_{L}}{\partial \mu}=2 \frac{\left(\gamma p_{L}^{\alpha}-p_{L}\right)\left(1-\gamma \alpha\left(p_{H}\left(p_{L}\right)\right)^{\alpha-1}\right)}{S^{\prime}\left(p_{L}\right)(1-\mu)^{2}}, \\
& \text { and } \frac{\partial p_{H}}{\partial \mu}=2 \frac{\left(\gamma p_{L}^{\alpha}-p_{L}\right)\left(\gamma \alpha\left(p_{L}\right)^{\alpha-1}-1\right)}{S^{\prime}\left(p_{L}\right)(1-\mu)^{2}} .
\end{aligned}
$$

Hence,

$$
\begin{aligned}
& \frac{\partial\left(\frac{p_{H}+p_{L}}{2}\right)}{\partial \mu}= \\
& \quad \frac{\left(\gamma p_{L}^{\alpha}-p_{L}\right)\left(\gamma \alpha p_{L}^{\alpha-1}-\gamma \alpha\left(p_{H}\left(p_{L}\right)\right)^{\alpha-1}\right)}{S^{\prime}\left(p_{L}\right)(1-\mu)^{2}} \\
& \quad<0,
\end{aligned}
$$

since by concavity

$$
\left(\gamma p_{L}^{\alpha}-p_{L}\right)\left(\gamma \alpha p_{L}^{\alpha-1}-\gamma \alpha p_{H}^{\alpha-1}\right)>0,
$$

and, from the proof of Proposition $1, S^{\prime}\left(p_{L}\right)<0$.

\section{Conclusion}

Our results suggest that enhancing the transparency of politics may not be a desirable thing to do. In particular, our analysis has pointed out a particular mechanism that may generate a perverse relationship between the transparency of politics and the quality of politicians. In future work, we plan to address empirically the relationship between the transparency of various aspects of political systems and the characteristics of the political class and their performance in office.

\section{REFERENCES}

Best, Heinrich, and Maurizio Cotta. 2000. Parliamentary Representatives in Europe 18482000: Legislative Recruitment and Careers in Eleven European Countries. Oxford: Oxford University Press.

Dal Bo, Ernesto. 2006. "Bribing Voters." Unpublished.

Gavazza, Alessandro, and Alessandro Lizzeri. 2006. "Transparency and Economic Policy." Unpublished.

Levy, Gilat. 2007. "Decision Making in Committees: Transparency, Reputation, and Voting Rules." American Economic Review. 97(1): 149-67.

Mattozzi, Andrea, and Antonio Merlo. 2005. "Political Careers or Career Politicians?" Unpublished.

Mattozzi, Andrea, and Antonio Merlo. 2006. "Mediocracy." Unpublished.

Merlo, Antonio. 2006. "Whither Political Economy? Theories, Facts and Issues." In Advances in Economics and Econometrics, Theory and Applications: Ninth World Congress of the Econometric Society, Vol. 1, ed. Richard Blundell, Whitney K. Newey, and Torsten Persson, 381-421. Cambridge: Cambridge University Press.

Prat, Andrea. 2005. "The Wrong Kind of Transparency." American Economic Review, 95(3): 862-77. 